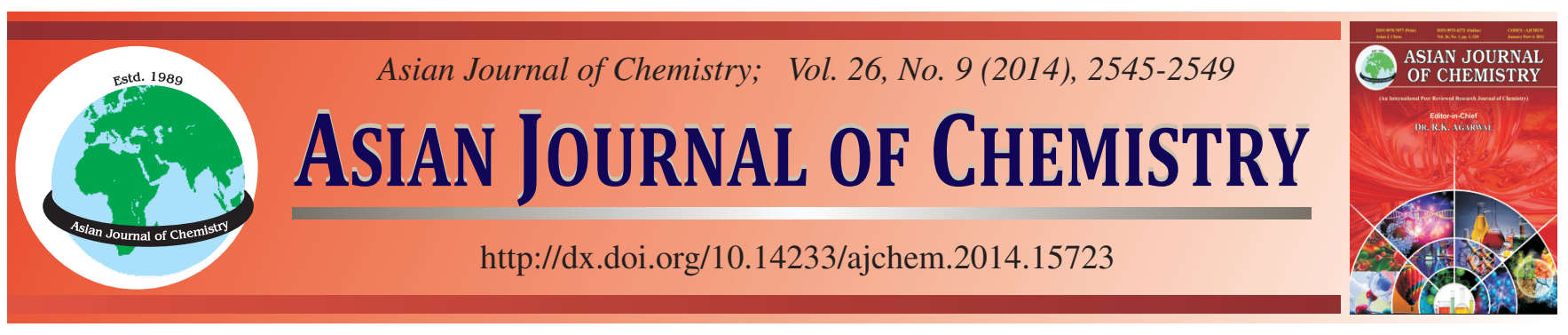

\title{
Preparation and Characterization of Activated Carbons Derived from Marine Green Algae Ulva fasciata sp.
}

\author{
R.P. SuRESh JEYAKUMAR ${ }^{1, *}$ and V. ChANDRASEKARAN ${ }^{2}$
}

${ }^{1}$ Department of Chemistry, Karpagam University, Coimbatore-641 021, India

${ }^{2}$ Department of Chemistry, Government Arts College (Autonomous), Salem-636 007, India

*Corresponding author: E-mail: rpsjoseph3@yahoo.co.in

Received: 3 May 2013;

Accepted: 3 February 2014;

Published online: 28 April 2014;

AJC-15065

\begin{abstract}
In present study, activated carbons were prepared from marine green algae Ulva fasciata sp. by chemical activation process and compared with the commercial activated carbon. Their characteristic properties such as moisture content, volatile matter, ash content, fixed carbon content, matter soluble in water, matter soluble in acid, $\mathrm{pH}$, bulk density, decolorizing power, iodine value, elemental analysis and surface area have been studied. Activated carbons prepared from marine green algae Ulva fasciata $s p$. have large amount of surface chemical groups present in the sample are good anchoring sites for adsorption. The microstructure of the prepared activated carbons was examined by SEM analysis, while the FTIR spectra analysis showed the surface functional groups and X-Ray fluorescence analysis showed oxide forms of elements present in the activated carbons.
\end{abstract}

Keywords: Algae, Ash content, Microstructure, Iodine value, Surface area.

\section{INTRODUCTION}

Activated carbons are carbonaceous materials that can be distinguished from elemental carbon by the oxidation of the carbon atoms found on the outer and inner surfaces ${ }^{1}$. These materials are characterized by their extraordinary large specific surface areas, well-developed porosity and tunable surfacecontaining functional groups ${ }^{2}$. These unique characteristics are responsible for its adsorptive properties, which are exploited in many different liquid and gas phase applications. Activated carbon is generally considered to exhibit a low affinity for water, which is an important property with respect to the adsorption of gases in the presence of moisture. Commercial activated carbon products are produced from organic materials that are rich in carbon, particularly coal, lignite, wood, nut shells, peat, pitches and cokes ${ }^{3}$.

They are of great interest in many economic sectors and concern many industries as diverse as food and beverage processing, chemical, petroleum, mining, nuclear and vacuum manufacturing. Some of these applications are highly demanding with regard to the surface chemistry and characteristics of these carbon adsorbents ${ }^{4}$. The major use of activated carbon is in solution purification and for the removal of taste, colour, odour and other objectionable impurities from liquids, water supplies and vegetable and animal oils. In recent years it has been increasingly used for the prevention of environmental pollution and antipollution laws have increased the sales of activated carbon for control of air and water pollution. Activated carbon is a broad-spectrum agent that effectively removes toxic and bio refractive substances such as insecticides, herbicides, chlorinated hydrocarbons and phenols, typically present in many water supplies ${ }^{5}$. Some of these applications are highly demanding with regard to the surface chemistry and characteristics of these carbon adsorbents ${ }^{6}$.

There are two basic process of producing activated carbon, physical activation and chemical activation. In physical activation process, the processes of carbonization and activation take place in two separate steps. The activating medium most commonly used were certain oxidizing gases like steam, carbon dioxide, air etc. This is a high temperature process as compared to that of chemical activation. In chemical activation, both the processes of carbonization and activation, takes place simultaneously. Here, the raw material which in most of the cases is of cellulosic nature, is impregnated or kneaded with certain inorganic salts and this impregnated mass is then carbonized at low temperatures to ultimately yield an active char, after washing with acid and water. The products obtained by the process of chemical activation are mostly used in liquid phase purification systems ${ }^{7}$. Adsorption of activated carbon is governed by the chemical nature of the aqueous phase, the solid phase and the chemical nature of the adsorbing organic ${ }^{8}$. Some of the advantages of activated carbon are high efficiency, 
minimization of chemical, regeneration of adsorbent and possibility of metal recovery9

Due to the growing need for activated carbons in our society and the high cost of raw materials and production, many researchers have attempted various wastes such as resins ${ }^{10}$, agricultural byproducts ${ }^{11}$ and dried sewage sludge $\mathrm{e}^{12,13}$ as raw materials and proposed new production methods ${ }^{14}$ for activated carbons with potential applications in pollution control. Commercial activated carbons are commonly produced from naturally occurring carbonaceous materials such as coal, wood and peat ${ }^{15}$. Activated carbon usually increases the cost of the treatment process. Its economical drawback has stimulated the interest to utilize low cost raw materials for the production of activated carbon ${ }^{16}$. Marine algae with large available quantities in many regions are a kind of promising biological resources. Many studies have showed that algae possess high metal binding capacities ${ }^{17,18}$, due to the presence of polysaccharides, proteins or lipid on the cell wall surface containing functional groups such as amino, hydroxyl, carboxyl and sulphate, which can act as binding sites for metals. The cell wall matrix of green algae contains complex hetero polysaccharides that can provide amino, carboxyl and sulphate groups ${ }^{19}$.

In the present study, activated carbons (CCUC, SSUC and SCUC) were prepared form marine green algae Ulva fasciata $s p$. and their physico-chemical properties compared to the commercially activated carbon. Their characterization studies such as proximate analysis, matter soluble in water, matter soluble in acid, $\mathrm{pH}$, bulk density, decolorizing power, iodine value, surface area, elemental analysis were done. The scanning electron microscopy, Fourier transform infrared spectra and $\mathrm{X}$-ray fluorescence analysis have also been studied.

\section{EXPERIMENTAL}

The green marine algae Ulva fasciata in the present study were collected from the coastal area of Kanyakumari district, Tamil Nadu, India. The collected algae were washed with tap water and further by deionized water several times to remove impurities. The washing process was continued till the removal of all dirt. The washed algae were then cut into small pieces and completely dried in sun light for 7 days. Then the dried algae Ulva fasciata were used for the preparation of activated carbons using physical and chemical activation methods. The dried algae were pretreated with calcium chloride, sodium sulphate and sodium cabonate salts respectively. It is further carbonized as three types, known as calcium chloride treated Ulva fasciata carbon (CCUC), sodium sulphate treated Ulva fasciata carbon (SSUC) and sodium carbonate treated Ulva fasciata carbon (SCUC).

Calcium chloride treated Ulva fasciata carbon (CCUC): The dried algae Ulva fasciata to be carbonized is impregnated with solution calcium chloride for $24 \mathrm{~h}$. Accordingly sufficient quantities were soaked well with $10 \%$ calcium chloride solution of $5 \mathrm{~L}$ capacity respectively so that the solution get well adsorbed for a period of $24 \mathrm{~h}$. At the end of $24 \mathrm{~h}$ the excess solution were decanted off and air dried. Then the materials were placed in muffle furnace carbonized at $400{ }^{\circ} \mathrm{C}$. The dried materials were powdered and activated in a muffle furnace kept at $800^{\circ} \mathrm{C}$ for a period of $10 \mathrm{~min}$. After activation, the carbon washed sufficiently with $4 \mathrm{~N} \mathrm{HCl}$ to remove the cations. Then the materials were washed with water to remove excess acid, dried and powdered ${ }^{20}$.

Sodium sulphate treated Ulva fasciata carbon (SSUC): In this method the dried algae Ulva fasciata to be carbonized were soaked in $10 \%$ solutions of sodium sulphate for a period of $24 \mathrm{~h}$. After impregnation, the liquid portion was decanted off and then dried. The dried mass was subjected to carbonization process at $400{ }^{\circ} \mathrm{C}$ powdered well and finally thermally activated at $800{ }^{\circ} \mathrm{C}$ for $10 \mathrm{~min}^{20}$.

Sodium carbonate treated Ulva fasciata carbon (SCUC): In this method the dried algae Ulva fasciata to be carbonized were soaked with $10 \%$ sodium carbonate solution for a period of $24 \mathrm{~h}$. After impregnation, the liquid portion was decanted off and the material dried. The dried mass was subjected to carbonization process at $400{ }^{\circ} \mathrm{C}$ powdered well and finally thermally activated at $800{ }^{\circ} \mathrm{C}$ for a period of $10 \mathrm{~min}^{20}$.

In the present study the powdered activated carbons (CCUC, SSUC and SCUC) of algae Ulva fasciata in the range of $150 \mu \mathrm{m}$ particle size were used. The physico-chemical properties of these Ulva fasciata activated carbons were compared with commercial activated carbon (CAC).

\section{Methods for determination of carbon characteristics}

Proximate analysis: The proximate analysis of a substance is a simple means of determining the distribution of products obtained when the coal sample is heated under specified conditions. Proximate analysis was carried out for all these carbons to determine moisture content, ash content, volatile matter and fixed carbon content. Proximate analysis is the most often used analysis for characterizing a material in connection with their utilization.

Determination of moisture content: About $10 \mathrm{~g}$ of the sample was weighed in a petri dish. The dish was placed in an electric oven maintained at $110 \pm 5^{\circ} \mathrm{C}$ for about $4 \mathrm{~h}$. The dish was covered, cooled in a desiccator and weighed. Heating, cooling and weighing was repeated at 30 min interval until the difference between the two consecutive weight was less than $5 \mathrm{mg}$.

$$
\text { Moisture content }(\%)=\frac{100 \times(\mathrm{M}-\mathrm{X})}{\mathrm{M}}
$$

where, M-mass in gram of the sample taken for the test, XMass in gram of the sample after drying

Determination of ash content: $2 \mathrm{~g}$ of sample under examination was weighted accurately into a silica crucible. The crucible and its contents were placed in an electric oven at $110 \pm 5^{\circ} \mathrm{C}$ for about $4 \mathrm{~h}$. The crucible was removed from the oven and the contents were ignited in an electric muffle furnace at a temperature of $1000{ }^{\circ} \mathrm{C}$ for about $3 \mathrm{~h}$. The process of heating and cooling was repeated until the difference between two consecutive weighing was less than $1 \mathrm{mg}$ (the ash was preserved for the determination of iron).

$$
\text { Ash content }(\%)=\frac{M_{1} \times 100}{M \times(100-X) / 100}
$$

where, $M_{1}=$ mass of ash in grams, $M=$ Mass of the sample taken for the test in gram, $\mathrm{X}=$ Percentage of moisture content present in the sample taken for the test. 
Determination of volatile matter (VM): $1 \mathrm{~g}$ of test sample dried at $105 \pm 10^{\circ} \mathrm{C}$ was weighted in a preheated volatile matter silica crucible. The crucible was kept in the muffle furnace at the temperature of $925 \pm 10^{\circ} \mathrm{C}$ and was taken out exactly after $7 \mathrm{~min}$. It is then cooled rapidly in a desiccator and weighed.

$$
\text { Volatile matter }(\%)=\frac{\left(\mathrm{M}_{2}-\mathrm{M}_{3}\right)}{\mathrm{M}_{1}} \times 100
$$

where, $\mathbf{M}_{1}=$ mass of sample, $\mathbf{M}_{2}=$ mass of crucible with sample, $\mathrm{M}_{3}=$ mass of crucible and sample after heating

Determination of fixed carbon (FC): Fixed carbon is calculated by subtracting the percentage of volatile matter and ash from 100.

$$
\text { Fixed carbon }(\%)=100-(\text { Volatile matter }+ \text { Ash content })
$$

Determination of $\mathbf{p H}: 10 \mathrm{~g}$ of the dried sample was weighed and transferred into a $1 \mathrm{~L}$ breaker. $300 \mathrm{~mL}$ of freshly boiled and cooled water (adjusted to $\mathrm{pH}$ 7.0) was added and heated to boiling. After digesting for $10 \mathrm{~min}$, solution was filtered while hot, rejecting the first $20 \mathrm{~mL}$ of the filtrate. The remaining filtrate was cooled to room temperature and the $\mathrm{pH}$ was determined using a $\mathrm{pH}$ meter.

Apparent density test: The apparent density of the material was obtainedby weighing $5 \mathrm{~g}$ of the produced activated carbon and transferring it into a $10 \mathrm{~mL}$ graduated cylinder. The cylinder was tamping with a rubber pad while activated carbon was being added until the entire original sample was transferred to the cylinder. Tamping was continued for 5 min until there was no further settling produced. The volume was recorded and the apparent density was calculated on the dry basis. The apparent density was calculated by dividing the weight of sample by volume.

Decolorizing power: About $0.1 \mathrm{~g}$ of the sample was transferred to a $50 \mathrm{~mL}$ glass stoppered flask. $1 \mathrm{~mL}$ of methylene blue solution $(0.15 \%)$ was added from a burette and shaken for $5 \mathrm{~min}$. Addition of methylene blue solution and shaking was continued till the blue colour persisted for at least $5 \mathrm{~min}$. Docolourising power of carbon is expressed in terms of milligrams of methylene blue adsorbed by $1 \mathrm{~g}$ of activated carbon.

\section{Decolourising power $(\mathrm{mg} / \mathrm{g})=1.5 \times \mathrm{V} / \mathrm{M}$}

where $\mathrm{V}=$ volume in $\mathrm{mL}$ of methylene blue solution consumed, $\mathrm{M}=$ mass of the sample in grams.

Determination of iodine value: To gain further knowledge of the porous structure of activated carbon, iodine adsorption from liquid phase was adopted ${ }^{21}$. The iodine value, defined as the amount of iodine adsorbed per gram of activated carbon at an equilibrium concentration of $0.02 \mathrm{~N}$, was measured according to the procedure established by the American Society for Testing and Materials (ASTM 2006).

Procedure of iodine value test: Iodine solution was standardized as $10 \mathrm{~mL}$ of $0.1 \mathrm{~N}$ iodine solution was taken in conical flask, 2 drops of starch solution was added to it. The pale yellow colour of iodine solution turned blue. Titration of the formed solution was done with $0.05 \mathrm{~N}$ sodium thiosulphate till it becomes colorless. Burette reading corresponds to blank reading (B). Exactly $0.2 \mathrm{~g}$ of activated carbon was weighed accurately. It was introduced into the iodine flask which should be completely dry. $40 \mathrm{~mL}$ of $0.1 \mathrm{~N}$ iodine solution was then added. The flask was shaken properly for $4 \mathrm{~min}$ and then filtered. The filtrate was collected in a dry flask and then $10 \mathrm{cc}$ of the filtrate was titrated against standard sodium thiosulphate solution using starch as indicator.

Calculations involved in iodine value estimation: Iodine value $=\mathrm{C} \times$ conversion factor conversion factor $=127 \times$ normality of iodine $\times 40 / \mathrm{Wt}$. of carbon $\times$ blank reading $\mathrm{C}=$ (B-A).

Determination of surface area (BET Method): Nitrogen adsorption at $77 \mathrm{~K}$ was utilized to determine specific surface areas and porosities of these carbon samples. A gas adsorption manometry apparatus was used in the $\mathrm{N}_{2}$ adsorption experiments $^{22}$. The specific surface area was determined through the BET equation. Micropore volumes were determined through this method and the Dubinin-Radushkevich equation.

\section{RESULTS AND DISCUSSION}

Elemental analysis shows that the carbon content of CAC is greater than CCUC, SSUC and CCUC. Even though the carbon content is less in the cases of CCUC, SSUC, SCUC and the percentage of other elements such as oxygen, hydrogen, nitrogen and chlorine is much higher than that of CAC. It shows that these elements may be present in the functional groups which may favour the removal of heavy metal ions from solutions. The results are shown in Table-1.

TABLE-1

ELEMENTAL ANALYSIS OF Ulva fasciata ACTIVATED CARBONS AND COMMERCIAL ACTIVATED CARBON

\begin{tabular}{ccccc}
\hline Elements (\%) & CCUC & SSUC & SCUC & CAC \\
\hline Carbon & 64.83 & 72.79 & 70.42 & 84.31 \\
Hydrogen & 4.15 & 4.35 & 3.85 & 1.60 \\
Oxygen & 11.62 & 16.37 & 13.88 & 5.49 \\
Nitrogen & 2.41 & 2.56 & 2.74 & 0.27 \\
Sulphur & 1.26 & 5.53 & 1.73 & 0.17 \\
Chlorine & 4.25 & 0.37 & 0.29 & 0.21 \\
\hline CCUC = Calcium chloride treated Ulva fasciata carbon \\
SSUC = Sodium sulphate treated Ulva fasciata carbon \\
SCUC = Sodium carbonate treated Ulva fasciata carbon \\
CAG = Commercial activated carbon
\end{tabular}

Result of proximate analysis of the carbons: Higher moisture content reduces the adsorption capacity of carbon by diluting the action of activated carbon. It could be known from Table-2, that the moisture content of SSUC is lesser than other activated carbons in the present study, hence which may be a better adsorbent than others.

Among the Ulva fasciata activated carbons lowest volatile matter is found in SCUC. During thermal activation, most of the non-carbon elements such as hydrogen, oxygen, nitrogen and sulphur may have been eliminated as volatile gaseous products by the pyrolytic which accounts for low volatile matter content of SCUC. Ash content is the inorganic, inert, amorphous and unstable portion present in the activated carbon and it arises from basic nature of raw material. Hence it is clear, lower percentage of ash content should be a good activated carbon. But all the Ulva fasciata activated carbons are found to have high ash contents when compared with CAC, which may be due to their coastal origin, activation method and their thermal activation at $800{ }^{\circ} \mathrm{C}$. From the elemental analysis analysis and proximate analysis it was clearly seen that there was not much difference in the fixed carbon content. Hence 
both are viable options for activated carbon production. The results of proximate analysis are shown in Table- 2 .

\section{TABLE-2}

PROXIMATE ANALYSIS AND OTHER CHARACTERS OF Ulva fasciata ACTIVATED CARBON

\begin{tabular}{lcccc}
\hline Component (\%) & CCUC & SSUC & SCUC & CAC \\
\hline Moisture content & 17.20 & 3.73 & 4.92 & 4.50 \\
Ash content & 12.71 & 22.20 & 17.35 & 6.77 \\
Volatile matter & 27.14 & 18.20 & 17.40 & 34.80 \\
Fixed carbon & 60.15 & 69.60 & 65.25 & 78.43 \\
\hline
\end{tabular}

Result of surface area analysis of the carbons: The surface area of the activated carbon is directly related to the porosity of the carbon. Surface area is the measurement of the extent of the pore surface developed within the matrix of the activated carbon. From the Table-3, it is observed that the surface area of CAC is low when compared with Ulva fasciata activated carbons. On the other hand average pore sizes of CCUC, SSUC and SCUC are much higher than that of CAC. But the lower surface area of Ulva fasciata activated carbons may be compensated by higher pore size. Hence Ulva fasciata activated carbons must be the good adsorbents than commercial activated carbon.

\begin{tabular}{|c|c|c|c|c|}
\hline \multicolumn{5}{|c|}{$\begin{array}{c}\text { TABLE-3 } \\
\text { EFFECT OF ACTIVATED CARBONS ON OTHER } \\
\text { PHYSICO-CHEMICAL PROPERTIES }\end{array}$} \\
\hline Properties & CCUC & SSUC & SCUC & $\mathrm{CAC}$ \\
\hline $\mathrm{pH}$ & 8.51 & 9.37 & 11.13 & 7.59 \\
\hline Matter soluble in water $(\%)$ & 2.03 & 0.98 & 1.28 & 3.06 \\
\hline Matter soluble in acid (\%) & 4.50 & 1.65 & 3.70 & 5.43 \\
\hline Surface area $\left(\mathrm{m}^{2} / \mathrm{g}\right)$ & 317.11 & 358.23 & 341.52 & 243.45 \\
\hline Pore volume $\left(\mathrm{cm}^{3} / \mathrm{g}\right)$ & 0.25 & 0.38 & 0.32 & 0.11 \\
\hline Pore size $(\AA)$ & 304.7 & 558.4 & 398.5 & 96.08 \\
\hline Iodine value $(\mathrm{mg} / \mathrm{g})$ & 619.2 & 788.5 & 715.3 & 527.5 \\
\hline Decolorizing power $(\mathrm{mg} / \mathrm{g})$ & 47.52 & 35.20 & 38.43 & 63.10 \\
\hline
\end{tabular}

Effect of activated carbons on iodine value and other characters: Iodine number is a fundamental parameter used to characterize performance of activated carbons. It is a measure of the micro pore content of the activated carbon and is obtained by the adsorption of iodine from solution by the activated carbon sample. Higher value of the iodine number indicates higher degree of activation. Table-3 shows the effect of Ulva fasciata activated carbons and commercial activated carbon on the iodine value. The iodine values of the activated carbons changed significantly with activating agents. The SSUC has the highest iodine value of $788.5 \mathrm{mg} / \mathrm{g}$, indicating that its pore surface and structure were the best developed. Table- 3 also suggested that the iodine values of CCUC and SCUC are greater than the value obtained for CAC.

The $\mathrm{pH}$ value of an activated carbon shows whether it is acidic or basic, $\mathrm{pH}$ value of CCUC, SSUC SCUC and CAC are shown in Table-3. It is well known that all the activated carbons are basic in nature $(\mathrm{pH}>7)$, which may be due to the corresponding carbonization with activating agents. The values of matter soluble in water and acid are lesser in the case of SSUC and SCUC than that of CCUC and CAC, which is due to the fact that more water soluble and acid soluble matter are present in CCUC and CAC.
FTIR analysis: Fourier transform infrared spectroscopy (FTIR) study was carried out to identify the functional groups present in the adsorbents in the $4000-400 \mathrm{~cm}^{-1}$ range. Some characteristic bands were obtained from the functional groups present in alcohols, phenols, carbonyls, carboxylic acids, hydroxyls, amides, ethers, aromatic phosphate and sulphate in Ulva fasciata activated carbons and CAC. FTIR analysis reveals that more functional groups are found in Ulva fasciata activated carbons than commercial activated carbons. Hence it is clear that Ulva fasciata activated carbons could be better adsorption ability than commercial activated carbons. The observed FTIR bands and the corresponding functional groups are tabulated in Table-4.

\begin{tabular}{|c|c|c|c|c|}
\hline \multicolumn{5}{|c|}{$\begin{array}{c}\text { TABLE- } 4 \\
\text { FTIR SPECTROSCOPIC ANALYSIS }\end{array}$} \\
\hline \multicolumn{4}{|c|}{ Wave number $\left(\mathrm{cm}^{-1}\right)$} & \multirow{2}{*}{ Possible functional groups } \\
\hline CCUC & SSUC & SCUC & $\mathrm{CAC}$ & \\
\hline 3650 & 3654 & 3651 & - & $\mathrm{OH}$ group of alcohols and phenols \\
\hline 3456 & 3464 & 3428 & 3420 & $\mathrm{O}-\mathrm{H}$ and $\mathrm{NH}$ groups \\
\hline 2355 & 2357 & 2343 & 2363 & P-H stretching \\
\hline 1618 & 1460 & 1482 & 1576 & $\begin{array}{l}\text { Primary and secondary amide (or) } \mathrm{C}=\mathrm{O} \\
\text { group }\end{array}$ \\
\hline 1121 & 1122 & 1121 & 1142 & C-O sym or asym stretching \\
\hline 883 & 862 & 830 & - & Aromatic phosphate (P-O-C) stretch \\
\hline 713 & 622 & 622 & - & $\mathrm{SO}_{3}$ group \\
\hline
\end{tabular}

Scanning electron microscope analysis: SEM photographs show that wide varieties of pores are present in activated carbon along with fibrous structure. Fig. 1 shows that the micrograph of the activated carbon CCUC, there are many thin white layers within the activated carbon structure and some undeveloped pores. Fig. 2 shows the micrograph of the activated carbon SSUC.

It could be seen from Fig. 2 that the white patches and soft materials disappeared, giving rise to clear pore structure. Fig. 3 shows the micrograph of the activated carbon SCUC, which is almost similar to micrograph of the SSUC. Fig. 4 shows that the micrograph of commercially activated carbon (CAC). It could be seen from Fig. 4 that poor pore structure, some furry materials and white patches are present on the activated carbon surface. From SEM micrograph analysis of activated carbons, it can be easily concluded that the huge and

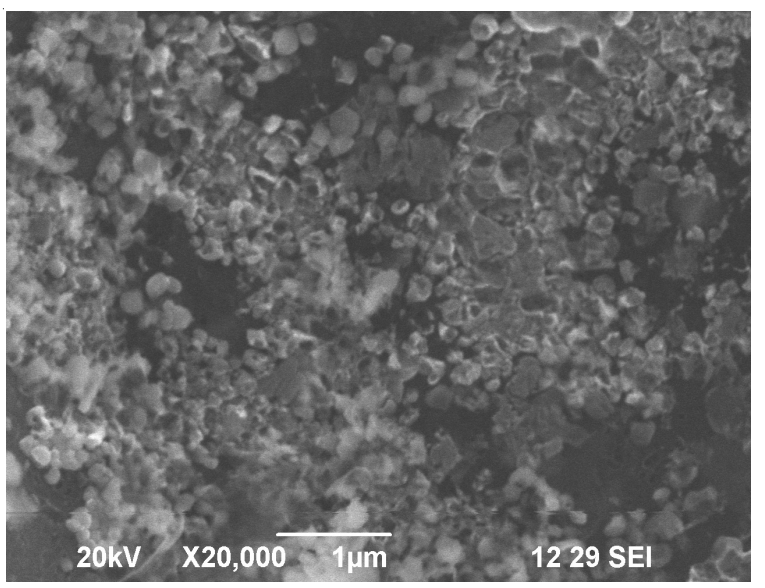

Fig. 1. Scanning micrograph of calcium chloride treated Ulva fasciata carbon 


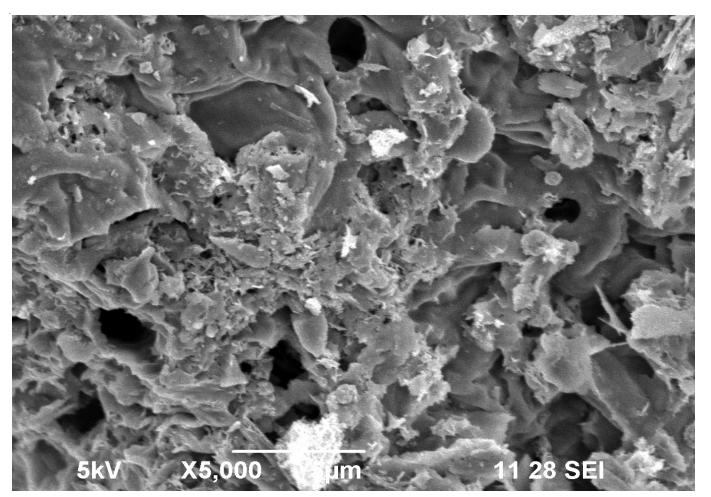

Fig. 2. Scanning micrograph of sodium sulphate treated Ulva fasciata carbon

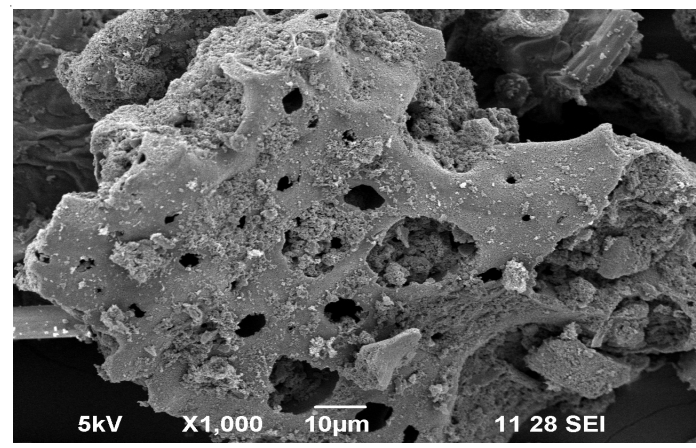

Fig. 3. Scanning micrograph of sodium carbonate treated Ulva fasciata carbon

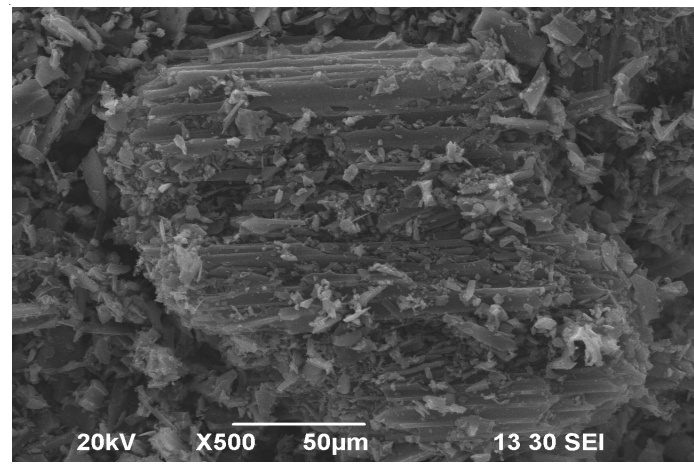

Fig. 4. Scanning micrograph of ommercial activated carbon

significant voids present on surface of SSUC and SCUC compared to CCUC and CAC indicated that SSUC and SCUC have more porous surface. Difference in surface morphology or porosity may be also responsible for different adsorption capacities of adsorbents.

Result of X-ray fluorescence analysis: The result of Xray fluorescence analysis is shown in Table-5. It could be seen from Table- 5 that the presence of oxide forms of various inorganic components in the activated carbons. The CCUC has higher oxides of calcium, which may be due to the chemical activation with activating agent calcium chloride salt.

Sodium sulphate treated Ulva fasciata carbon has higher oxides of sulphur, which may be due to the introduction of sulphate groups during chemical activation with sodium sulphate. X-Ray fluorescence analysis also suggested that oxides of sodium are higher in SSUC and SCUC, which may have been the chemical activation with sodium sulphate and sodium carbonate respectively.

\begin{tabular}{ccccc}
\multicolumn{5}{c}{ TABLE- 5 } \\
\multicolumn{5}{c}{ X-RAY FLUORESCENCE ANALYSIS } \\
\hline Component (\%) & CCUC & SSUC & SCUC & CAC \\
\hline Loss on ignition & 81.562 & 78.940 & 80.251 & 95.633 \\
$\mathrm{CaO}$ & 4.509 & 1.253 & 0.834 & 0.249 \\
$\mathrm{P}_{2} \mathrm{O}_{5}$ & 2.850 & 2.477 & 2.402 & 0.073 \\
$\mathrm{~K}_{2} \mathrm{O}$ & 2.138 & 2.825 & 2.382 & 0.069 \\
$\mathrm{MgO}$ & 2.228 & 2.530 & 3.216 & 0.084 \\
$\mathrm{SO}_{3}$ & 1.037 & 3.206 & 0.862 & 0.251 \\
$\mathrm{SiO}_{2}$ & 1.641 & 2.136 & 1.935 & 0.362 \\
$\mathrm{Fe}_{2} \mathrm{O}_{3}$ & 2.273 & 2.812 & 3.108 & 1.271 \\
$\mathrm{Al}_{2} \mathrm{O}_{3}$ & 0.264 & 0.205 & 0.259 & 0.154 \\
$\mathrm{Na}_{2} \mathrm{O}$ & 0.130 & 3.183 & 3.817 & 0.052 \\
$\mathrm{ZnO}$ & 0.083 & 0.065 & 0.061 & 0.017 \\
$\mathrm{MnO}$ & 0.047 & 0.025 & 0.018 & 0.005 \\
$\mathrm{TiO}_{2}$ & 0.036 & 0.014 & 0.016 & 0.003 \\
$\mathrm{CuO}$ & 0.009 & 0.003 & 0.004 & 0.002 \\
\hline
\end{tabular}

\section{Conclusion}

The results of this study showed that it is viable to prepare activated carbons with relatively high pore size and pore volumes from Ulva fasciata by direct chemical activation. From elemental analysis we could know that activated carbons prepared from Ulva fasciata (CCUC, SSUC and SCUC) have higher percentage of elements such as oxygen, hydrogen, nitrogen and chlorine than with CAC. Therefore more chemical functional groups may be present in Ulva fasciata carbns than in CAC, which may favour to remove heavy metal ions from solutions. Among the activated carbons higher iodine value of SSUC $(788.5 \mathrm{mg} / \mathrm{g})$ indicates higher degree of activation. Hence it is very clear to know that SSUC might be a better adsorbent than others.

\section{REFERENCES}

1. J.S. Mattson and H.B. Mark, Activated Carbon, New York, Dekker (1971).

2. F.S. Baker, C.E. Miller, A.J. Repic, and E.D. Tolles, Activated Carbon, Kirk-Othmer Encycolpedia of Chemical Technology, vol. 4, p. 1015 (1992).

3. Kirk-Othmer, Encyclopedia of Chemical Technology, John Wiley \& Sons Inc. (2003).

4. R.C. Bansal, J.B. Donnet and F. Stoeckli, Active Carbon, Marcel Dekker, New York, p. 49 (1988).

5. A. Bagreev, H. Rahman and T.J. Bandosz, Carbon, 39, 1319 (2001).

6. G.G. Stavropoulos and A.A.Zabaniotou, Microporous Mater., 82, 79 (2005).

7. O. Kadlec, A. Varhanikova and A. Zukal, Carbon, 8, 321 (1970).

8. B.A. Akash and W.S. O'Brien, Int. J. Energy Res., 20, 913 (1996).

9. N. Ahalya, Res. J. Chem. Environ., 7, 71 (2003).

10. Z. Yue, J. Economy and G. Bordson, J. Mater. Chem., 16, 1456 (2006).

11. K.M. Lee and G. Bordson, Water Sci. Technol., 47, 41 (2003).

12. F.S. Zhang, J.O. Nriagu and H. Itoh, Water Res., 39, 389 (2005).

13. S. Rio, L.L. Coq, C. Faur and P.L. Cloirec, Water Sci. Technol., 53, 237 (2006).

14. J.A. Menendez, A. Dominguez, M. Inguanzo and J.J. Pis, J. Anal. Appl. Pyrol., 74, 406 (2005).

15. F. Rozada, L.F. Calvo and A.I. Garcia, Bioresour. Technol., 87, 221 (2003).

16. S. Rengaraj, S.-H. Moon, R. Sivabalan, B. Arabindoo and V. Murugesan, Waste Manage., 22, 543 (2005).

17. G.J. Ramelow, D. Fralick and Y. Zhao, Microbios, 72, 81 (1992).

18. Z.R. Holan and B. Volesky, Biotechnol. Bioeng., 43, 1001 (1994).

19. A.D. Andrade, M.C.E. Rollemberg and J.A. Nóbrega, Process Biochem., 40, 1931 (2005).

20. S. Karthikeyan, P. Sivakumar and P.N. Palanisamy, E-J. Chem., 5, 409 (2008).

21. M.J. Martin, A. Artola, M.D. Balaguer and M. Rigola, Chem. Eng. J., 94, 231 (2003).

22. F. Rouquerol, J. Rouqoerol and K.S.W. Sing, Adsorption by Powders and Porous Solids: Principles, Methodology and Applications, Academic Press (1999). 